\title{
Apoptosis-associated microRNAs are modulated in mouse, rat and human neural differentiation
}

\author{
Márcia M Aranha', Daniela M Santos ${ }^{1}$, Joana M Xavier ${ }^{1}$, Walter C Low ${ }^{2,3}$, Clifford J Steer ${ }^{4,5}$, Susana Solá1, \\ Cecília MP Rodrigues ${ }^{1 *}$
}

\begin{abstract}
Background: MicroRNAs (miRs or miRNAs) regulate several biological processes in the cell. However, evidence for miRNAs that control the differentiation program of specific neural cell types has been elusive. Recently, we have shown that apoptosis-associated factors, such as p53 and caspases participate in the differentiation process of mouse neural stem (NS) cells. To identify apoptosis-associated miRNAs that might play a role in neuronal development, we performed global miRNA expression profiling experiments in NS cells. Next, we characterized the expression of proapoptotic miRNAs, including miR-16, let-7a and miR-34a in distinct models of neural differentiation, including mouse embryonic stem cells, PC12 and NT2N cells. In addition, the expression of antiapoptotic miR-19a and 20a was also evaluated.

Results: The expression of miR-16, let-7a and miR-34a was consistently upregulated in neural differentiation models. In contrast, expression of miR-19a and miR-20a was downregulated in mouse NS cell differentiation. Importantly, differential expression of specific apoptosis-related miRNAs was not associated with increased cell death. Overexpression of miR-34a increased the proportion of postmitotic neurons of mouse NS cells.
\end{abstract}

Conclusions: In conclusion, the identification of miR-16, let-7a and miR-34a, whose expression patterns are conserved in mouse, rat and human neural differentiation, implicates these specific miRNAs in mammalian neuronal development. The results provide new insights into the regulation of neuronal differentiation by apoptosis-associated miRNAs.

\section{Background}

Adult neural stem (NS) cells and embryonic stem (ES) cells are capable of differentiating into multiple cell types of the adult nervous system [1,2]. This unique property promises future medical applications, ranging from regenerative medicine to drug screening. However, the therapeutic use of NS cells and ES cells will require the identification of cellular conditions that promote the efficient commitment of these progenitors to particular cell phenotypes.

Much progress has been made toward the elucidation of specific differentiation signaling pathways. Surprisingly, recent evidence suggests a functional role for apoptosis-associated proteins such as p53 [3,4], caspases [5] and Bcl-2 [6] in differentiation and development. In

\footnotetext{
* Correspondence: cmprodrigues@ff.ul.pt

${ }^{1}$ Research Institute for Medicines and Pharmaceutical Sciences, Faculty of

Pharmacy, University of Lisbon, Lisbon 1649-003, Portugal

Full list of author information is available at the end of the article
}

addition, the recent discovery of microRNAs (miRs or miRNAs) introduced a novel type of regulatory control of gene expression during developmental processes $[7,8]$. miRNAs are a class of endogenous noncoding, highly conserved RNAs of $\sim 22$ nucleotides in length [9]. They regulate mRNA expression either by translation repression or cleavage of targeted mRNA [8]. In the past few years, our understanding of miRNAs has expanded, and a role for apoptosis-associated miRNAs in cell differentiation is emerging.

Let-7a, a member of the let-7 family, is associated with apoptosis by directly targeting caspase-3 [10]. Let-7 was first identified in Caenorhabditis elegans and reported to control the timing of fate specification during larval development [11]. In addition, let-7a was also implicated in neuronal differentiation $[12,13]$. However, the mechanism by which let-7a regulates cell differentiation is unknown. 
Members of the miR-34 family are direct p53 targets, and their upregulation induces apoptosis and cell cycle arrest [14-19]. In this regard, miR-34a has been shown to regulate genes involved in cell cycle control and apoptosis, including cyclin-dependent kinase 4 (CDK4), CDK6, cyclin D1, E2F3 and SIRT [17,20,21]. A role for miR-34a in megakaryocytic differentiation was recently reported, where the miRNA regulates the expression of MYB, and CDK4 and CDK6, thus promoting cell cycle arrest [22]. Furthermore, miR-34a is involved in dendritic cell differentiation [23], and is required for proper differentiation of mouse ES cells by targeting Sirt1 [24].

miR-16 is implicated in induction of apoptosis by targeting $\mathrm{Bcl}-2$ [25], and is involved in cell cycle regulation by targeting CDK6, cell division cycle protein 27 (CDC27), the caspase recruitment domain-containing protein 10 (CARD10), cyclin D1 and cyclin E [26-28]. Nevertheless, an involvement of miR-16 in cell differentiation is virtually unknown.

To gain further insight into the role of apoptosis-associated factors during cell differentiation, we monitored specific apoptosis-associated miRNAs during NS cell differentiation. Our results showed that the differential expression of miR-16, let-7a and miR-34a during mouse NS cell differentiation was not associated with cell death. In addition, upregulation of these miRNAs observed in distinct models of neural differentiation strongly suggests that apoptosis-associated miRNAs may play a role in differentiation.

\section{Methods \\ Cell Lines \\ Mouse NS Cells}

Mouse NS cells containing a constitutively expressed marker for green fluorescent protein (GFP) were used to investigate the process of neural differentiation. Primary cells were obtained from central nervous system tissue of embryonic mice and cultured primarily as previously described [29-31]. Mouse NS cells were maintained as neurospheres in undifferentiation medium, serum-free, 1:1 mix of DMEM/F12 (Invitrogen Corp., Grand Island, NY) with $1 \times \mathrm{N}-2$ supplement (Invitrogen Corp.), 20 $\mathrm{ng} / \mathrm{ml}$ epidermal growth factor (EGF) (R \& D Systems Inc., Minneapolis, MN), $20 \mathrm{ng} / \mathrm{ml}$ basic fibroblast growth factor (bFGF) (PeproTech EC, London, UK), and $1 \%$ penicillin-streptomycin (Invitrogen Corp.), at $37^{\circ} \mathrm{C}$ in humidified atmosphere of $5 \% \mathrm{CO}_{2}$. Subculture occurred at day 7 with mechanical dissociation of neurospheres. The differentiation of mouse NS cells in vitro was induced by culturing dissociated cells in differentiation medium containing DMEM/F12 with $1 \times \mathrm{N}-2$ supplement, $100 \mathrm{ng} / \mathrm{ml} \mathrm{bFGF,} \mathrm{10 \%} \mathrm{fetal} \mathrm{bovine} \mathrm{serum} \mathrm{(FBS)}$ (Invitrogen Corp.), $500 \mathrm{nM}$ all-trans retinoic acid (Sigma Chemical Co., St. Louis, MO), $50 \mu \mathrm{M}$ taurine
(Sigma Chemical Co.), $10 \mathrm{ng} / \mathrm{ml}$ transforming growth factor- $\beta 2$ (TGF- $\beta 2$ ) (R \& D Systems Inc.) and $1 \%$ penicillin-streptomycin in tissue culture plates pre-coated with poly-D-lysine (Sigma Chemical Co.). The culture medium was changed every 3 days. Differentiated cells at $5 \times 10^{4}$ cells $/ \mathrm{ml}$ were fixed at different time points, and processed for immunostaining and evaluation of differentiation. Cultures at $5 \times 10^{5}$ cells $/ \mathrm{ml}$ were processed for western blot and PCR analysis.

In parallel experiments, cell death was prevented by adding tauroursodeoxycholic acid (TUDCA; Sigma Chemical Co.) to the culture medium. Briefly, cells with 3 days of differentiation were treated with $50 \mu \mathrm{M}$ of TUDCA for 72 hours. At 6 days, cells were collected and processed for evaluation of apoptosis and miRNA expression.

miR-34a expression was modulated using $100 \mathrm{nM}$ of precursor control and pre-miR-34a (Applied Biosystems, Foster City, CA). Mouse NS cells $\left(2.5 \times 10^{5}\right.$ cells $\left./ \mathrm{ml}\right)$ were transfected at 3 or 5 days of differentiation using Lipofectamine 2000 (Invitrogen Corp) following manufacturer's instructions.

\section{Mouse ES Cells}

The ES cell line 46C (Sox1-GFP) [32] was grown and maintained as previously reported [33] and induced to differentiate using a monolayer protocol. Specifically, ES cells were plated in serum-free medium ESGRO Complete Clonal Grade medium (Millipor Inc.) at high density. After 24 hours, ES cells were gently dissociated and plated onto $0.1 \%(\mathrm{v} / \mathrm{v})$ gelatin-coated tissue culture plastic at $1 \times 10^{4}$ cells $/ \mathrm{cm}^{2}$ in RHB-A media (StemCell Science Inc.). For replating on day 4 , cells were dissociated and plated at $2 \times 10^{4}$ cells $/ \mathrm{cm}^{2}$ in laminin-coated tissue culture plastic, using RHB-A medium supplemented with $5 \mathrm{ng} / \mathrm{ml}$ murine bFGF (PeproTech EC, London, UK). Cells at days 4 and 8 of differentiation were collected to evaluate expression levels of differentiation markers and apoptosis-associated miRNAs. A positive control for neural differentiation was also included at day 8 using LY411575, a $\gamma$-secretase inhibitor known to inhibit the Notch pathway and thus enhance neuronal differentiation. Cells were supplemented with either

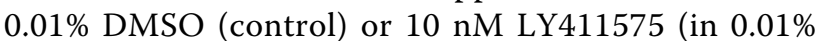
DMSO) for 12 hours. LY411575-treated cells and respective controls were photographed under an inverted microscope Leica DMIL using a DC200 camera (Leica Wetzlar, Germany)

\section{PC12 Cells}

Rat adrenal pheochromocytoma (PC12) cells were propagated in RPMI 1640 medium (Invitrogen Corp.) supplemented with $10 \%$ horse serum (Invitrogen Corp.), $5 \%$ FBS (Invitrogen Corp.) and appropriate antibiotics in an humidified incubator maintained at $37^{\circ} \mathrm{C}$ with $5 \% \mathrm{CO}_{2}$. PC12 cells were differentiated in RPMI 1640 medium 
containing $1 \%$ horse serum and antibiotics with either none, 5 or $50 \mathrm{ng} / \mathrm{ml}$ mouse nerve growth factor, (NGF 2.5S) (Chemicon, Temecula, CA) at 24 hours. Differentiation medium was replaced and fresh NGF 2.5 D was added every third day to differentiating cells. Cells were collected at 1, 2, 4 and 7 days prior to differentiation to evaluate expression levels of apoptosis-associated miRNAs.

\section{NT2N Cells}

The human teratocarcinoma-derived Ntera2/D1 neuronlike (NT2N) cells were obtained based on standard protocols with minor alterations [34,35]. Briefly, cells were differentiated by treating adherent dividing cells with 10 $\mu \mathrm{M}$ all-trans retinoic acid (Sigma Chemical Co.) for up to 3 weeks. Cells were collected at various time points (0,14 and 21 days); and for some a replate onto Matrigel coated culture dishes after 14 days of retinoic acid was performed. Replated cells were incubated with mitosis inhibitors $(1 \mu \mathrm{M}$ cytosine $\mathrm{D}$-arabinofuranoside, 10 $\mu \mathrm{M}$ fluorodeoxyuridine, $10 \mu \mathrm{M}$ uridine) (Sigma Chemical Co.), in the absence of retinoic acid, and collected 7 days after treatment to evaluate expression levels of apoptosis-associated miRNAs.

RNA isolation and semiquantitative reverse-transcriptasepolymerase chain reaction (RT-PCR)

Total RNA was isolated from mouse NS cells, PC12 and NT2N cells by TRIzol reagent (Invitrogen Corp.) according to manufacturer's protocol. ES cell RNAs were extracted using High Pure RNA Isolation kit (Roche Diagnostics), with the inclusion of DNAse I treatment according to manufacturer's instructions. For semiquantitative RT-PCR, 0.5-1 $\mu$ g of total RNA from NS and ES cells were reverse-transcribed using oligo(dT) (Integrated DNA Technologies Inc., Coralville, IA) and SuperScript II reverse transcriptase (Invitrogen Corp.). Specific oligonucleotide primer pairs were incubated with cDNA template for PCR amplification using the Expand High Fidelity ${ }^{\text {PLUS }}$ PCR System from Roche Applied Science. The following sequences were used as primers: Nestin sense 5'-CTGGAACAGAGATTGGAAGGCCGCT-3'; Nestin antisense $5^{\prime}$-GGATCCTGTGTCTTCAGAAA GGCTGTCAC-3'; Mash1 sense 5'-AGATGAGCAAGGT GGAGACG-3'; Mash1 antisense 5'-TGGAGTAGTTGG GGGAGATG-3'; Ngn1 sense 5'-ATGCCTGCCCC TTTGGAGAC-3'; Ngn1 antisense 5'-TGCATGCGGTT GCGCTCGC-3'; Ngn2 sense 5'-ACCGCATGCACAACCTAAAC-3'; Ngn2 antisense 5'-AGCGCCCAGATGTAATTGTG-3'; b-III tubulin sense 5'-AATGAG GCCTCCTCTCACAA-3'; b-III tubulin antisense 5'-CTTGCTGATGAGCAGTGTGC-3'; GFAP sense 5'-CCAAACTGGCTGATGTCTACC-3'; and GFAP antisense 5'-GCTTCATGTGCCTCCTGTCTA-3', GAPDH sense 5'-ATTCAACGGCACAGTCAAGG-3'; and
GAPDH antisense 5' TGGATGCAGGGATGATGTTC$3^{\prime}$. The ribosomal RNA subunit $28 \mathrm{~S}$ was used as control when using mouse NS cells, while GAPDH was used as control in mouse ES cells.

\section{Preparation of labeled RNA and array hybridization}

Microarray analysis was performed using a custom microarray platform, highly sensitive, allowing the profiling of even weakly expressed miRNAs [36]. Briefly, a miRNA probe set containing $\sim 1140$ oligonucleotides as probes, complementary to Caenorhabditis elegans, Drosophila, zebra fish, mouse, rat and human miRNAs was purchased from Invitrogen. The set also included a number of internal and negative control probes. Oligonucleotides were printed in quadruplicates on Corning GAPSII-coated slides in the Microarray Facility at the University of Minnesota. For RNA labeling, $25 \mu \mathrm{g}$ of total RNA was ligated to $0.5 \mu \mathrm{g}$ of a synthetic linker, pCU-DY547 (Dharmacon, Lafayette, CO, USA). To control the hybridization process, reference DNA oligonucleotides complementary to a subset of mammalian miRNAs were combined and labeled with a ULYSIS Alexa Fluor 647 Kit (Invitrogen Corp.). Labeled RNAs and DNAs were then mixed and hybridized to microarray slides [37]. Finally, slides were scanned with a ScanArray 5000 machine (Perkin Elmer, Waltham, MA, USA). Microarray images were processed with Bluefuse software (BlueGnome, Cambridge, UK) to quantify pixel intensities. Individual spots on the slides were further inspected to exclude abnormal spots from subsequent calculations.

\section{Evaluation of miRNAs expression levels by quantitative Real Time-PCR}

Real-time PCR was performed in an Applied Biosystems 7300 Sequence Detection System (Applied Biosystems, Foster City, CA). Ten nanograms of total RNA were reverse transcribed using a $\operatorname{TaqMan}^{\circledR}$ MicroRNA Reverse Transcription (RT) kit from Applied Biosystems. Each $\mathrm{RT}$ reaction contained 1x stem-loop $\mathrm{RT}$ specific primer, $1 x$ reaction buffer, $0.25 \mathrm{mM}$ each of dNTPs, $3.33 \mathrm{U} / \mu \mathrm{l}$ Multiscribe RT enzyme and $0.25 \mathrm{U} / \mu \mathrm{l}$ RNase inhibitor. The $15-\mu \mathrm{l}$ reactions were incubated for $30 \mathrm{~min}$ at $16^{\circ} \mathrm{C}$, $30 \mathrm{~min}$ at $42^{\circ} \mathrm{C}$, and $5 \mathrm{~min}$ at $85^{\circ} \mathrm{C}$ and then held at $4^{\circ} \mathrm{C}$. The PCR reaction was performed using a standard TaqMan ${ }^{\circledR}$ PCR kit protocol (Applied Biosystems). Briefly, following the RT step, $1.33 \mu \mathrm{l}$ of the RT reaction were combined with $1 \mu$ l of a TaqMAn MicroRNA Assay (20x; forward primer, reverse primer and probe) and $17.67 \mu \mathrm{l}$ of TaqMan $^{\circledR}$ Universal PCR Master Mix, No AmpErase ${ }^{\oplus} \mathrm{UNG}$ in a $20 \mu \mathrm{l}$ final volume. The reactions were incubated at $95^{\circ} \mathrm{C}$ for $10 \mathrm{~min}$, followed by 40 cycles of $95^{\circ} \mathrm{C}$ for $15 \mathrm{~s}$ and $60^{\circ} \mathrm{C}$ for $1 \mathrm{~min}$; and were run in triplicate. miRNA expression levels relative to GAPDH (mouse NS cells, ES cells, and PC12) or 
RNU6B (NT2N) were calculated on the basis of $\Delta \Delta C \mathrm{t}$ method. GeNorm and Norm-Finder were used to identify the best stable combination of reference genes/single gene for normalization in real-time PCR assays. Calibration was set using undifferentiated mouse NS cells, mouse ES cells with 4 days of differentiation or untreated with LY411575, PC12 with 1 day of differentiation and undifferentiated NT2N cells or non-replated NT2N cells. The $\mathrm{n}$-fold change in miRNAs expression was determined according to the method of $2^{-\Delta \Delta C T}$.

\section{Immunoblotting}

Steady-state levels of $\beta$-III tubulin, neuronal nuclei $(\mathrm{NeuN})$ and glial fibrillary acidic protein (GFAP) were determined by Western blot. Total protein extracts of mouse NS cells were prepared in lysis buffer, following standard established protocols. Protein content was measured by the Bio-Rad protein assay kit according to the manufacture's specification, using bovine serum albumin as standard. 50-80 $\mu \mathrm{g}$ of total protein extracts were separated on $12 \%$ sodium dodecyl sulphate-polyacrylamide electrophoresis gel and then subjected to immunoblots using primary mouse monoclonal antibody reactive to $\beta$-III tubulin (Tuj1, Covance, Princeton, NJ), NeuN (MAB377, Chemicon International), and GFAP (MAB360, Chemicon International). Blots were subsequently incubated with secondary antibodies conjugated with horseradish peroxidase (Bio-Rad Laboratories, Hercules, CA, USA). Finally, membranes were processed for protein detection using Immobilon (Millipore Corporation, Billerica, MA) or SuperSignal reagent (Pierce, Rockford, IL). Ponceau S staining was used to assess equal gel loading [38].

\section{Immunocytochemistry}

Mouse NS cells were fixed with paraformaldehyde (4\% $\mathrm{w} / \mathrm{v}$ ) in phosphate-buffered saline (PBS) and blocked for 1 hour at room temperature in PBS containing $0.1 \%$ Triton-X-100, 1\% FBS, and 10\% normal donkey serum (Jackson ImmunoResearch Laboratories, Inc., West Grove, PA). Subsequently, cells were incubated with either anti- $\beta$-III tubulin (rabbit, polyclonal; Chemicon International) or anti-GFAP antibodies (mouse, monoclonal; Chemicon International) at a dilution of 1:1000 in blocking solution, overnight at $4{ }^{\circ} \mathrm{C}$. Cells were then incubated with either anti-mouse or anti-rabbit IgG conjugated to AMCA (Jackson ImmunoResearch Laboratories, Inc.) and Alexa 594 (Molecular ProbesInvitrogen), respectively, for 2 hour at room temperature. Samples were mounted using Fluoromount $-\mathrm{G}^{\mathrm{TM}}$ (Beckman Coulter, Inc.). Fluorescence microscopy assessments were performed with a Zeizz AX10 microscope (Carl Zeiss, Jena, Germany) equipped with a Leica DFC490 camera (Leica Weitzlar, Germany). Living undifferentiated cells were photographed under an inverted microscope Leica DMIL with a DC200 camera (Leica Weitzlar, Germany).

\section{Assessment of apoptosis}

Apoptosis was assessed by evaluating DNA fragmentation, nuclear morphology and phosphatidylserine exposure.

Evaluation of DNA fragmentation by TUNEL assay. Apoptosis-induced DNA fragmentation was determined using the transferase mediated deoxyuridine triphosphate (dUTP)-digoxigenin nick-end labeling (TUNEL) assay. Cells were fixed with $4 \%(\mathrm{w} / \mathrm{v})$ paraformaldehyde and processed using an Apoptag in situ apoptosis detection kit according to the manufacturer's protocol (Chemicon Int., Temecula, CA). The samples were examined using a Leica DM 2500 bright-field microscope (Leica Weitzlar, Germany).

Morphologic evaluation of apoptosis. Hoechst labeling of mouse NS cells was used to detect apoptotic nuclei. In brief, the medium was gently removed at the indicated times with minimal detachment of the cells. Attached cells were fixed with $4 \%(\mathrm{w} / \mathrm{v})$ paraformaldehyde in PBS, $\mathrm{pH}$ 7.4 , for 10 minutes at room temperature, incubated with Hoechst dye 33258 (Sigma Chemical Co.) at $5 \mu \mathrm{g} / \mathrm{ml}$ in PBS for 5 minutes, washed with PBS and mounted using PBS:glycerol (3:1, v/v). Microscopy assessments were performed with a Zeizz AX10 microscope (Carl Zeiss, Jena, Germany) equipped with a Leica DFC490 camera (Leica Weitzlar, Germany). Normal nuclei showed non-condensed chromatin dispersed over the entire nucleus. Apoptotic nuclei were identified by condensed chromatin, contiguous to the nuclear membrane, as well as nuclear fragmentation of condensed chromatin.

Cytofluorometric analysis of apoptosis. Apoptotic cells were quantified by cytofluorometric analysis using a FACSCalibur (Becton Dickinson, Mountain View, CA) as described previously [39]. Cells were stained with the vital dye propidium iodide (PI; $5 \mu \mathrm{g} / \mathrm{mL}$; Sigma, Steinheim, Germany) and concomitantly with Annexin-VAPC (eBioscience, Inc.) according to manufacturer's instructions to determine the phosphatidylserine exposure. Data were statistically evaluated using FlowJo software (Tree Star, Inc, Ashland, OR).

\section{Flow Cytometry}

Cells were trypsinized (0.025\% trypsin/EDTA; Invitrogen Corp.) and harvested in $\mathrm{Ca}^{2+}$-free and $\mathrm{Mg}^{2+}$-free PBS and $2 \%$ FBS. After washing, $0.5-1 \times 10^{6}$ cells were fixed with paraformaldehyde $(4 \% \mathrm{w} / \mathrm{v})$ in PBS for $20 \mathrm{~min}$ on wet ice, and blocked for $20 \mathrm{~min}$ in PBS, containing $0.25 \%$ saponin (Fluka, Biochemika, Switzerland) and 5\% normal donkey serum (Jackson ImmunoResearch Laboratories, Inc., West Grove, PA). Subsequently, cells 
were incubated with anti-NeuN (MAB377; Chemicon International) at a dilution of 1:20 in PBS, containing $0.1 \%$ saponin and $5 \%$ normal donkey serum, for $30 \mathrm{~min}$. Cells were then incubated with anti-mouse antibody conjugated to Cy5 (Jackson ImmunoResearch Laboratories, Inc.), for $20 \mathrm{~min}$. Cells were analyzed using a FACSCalibur (Becton Dickinson, Mountain View, CA).

\section{Statistical Analysis}

Results from different groups were compared using the Student's t test, or one-way ANOVA. Kruskal-Wallis or the Mann-Whitney $U$ tests were also used whenever the assumptions of the parametric test were not satisfied. Values of $p<0.05$ were considered statistically significant. All statistical analysis was performed with GraphPad InStat software (GraphPad Software, Inc, San Diego, CA).

\section{Results \\ NS cells have both neurogenic and gliogenic potential in vitro}

It is known that both embryonic neural tissue and certain regions of the adult vertebrate central nervous system contain resident populations of progenitor/precursor stem cells [40]. NS cells can be isolated and expanded as undifferentiated floating clusters called neurospheres in the presence of bFGF and/or EGF [41]. In addition, NS cells have the ability to differentiate into neurons, astrocytes and oligodendrocytes in a time controlled fashion [42]. Thus, NS cells represent a powerful in vitro model system for studying and elucidating the molecular mechanisms that underlie neural differentiation. Using mouse NS cells constitutively expressing GFP (Figure 1A), we confirmed the differentiation potential toward neuronal and glial fates by monitoring the appearance of various cell-specific markers.

The proneural basic helix-loop-helix (bHLH) transcription factor Neurogenin1 (Ngn1) was not expressed in neurospheres, while Mash1 was readily detected (Figure 1B). Following incubation in differentiation medium, cells displayed a sharp increase in markers for neurons and neural precursors. Ngn1 was readily detected at 6 hours and tended to decrease during cell differentiation. Mash1 was slightly increased but not significantly modulated. Upregulation of proneural bHLH transcription factors was associated with a subsequent increase in $\beta$-III tubulin at both the mRNA and protein levels, indicating that neurogenesis is induced early after cell incubation in differentiation medium. At the protein level, $\beta$-III tubulin expression peaked at 1 day of differentiation and gradually decreased thereafter (Figure 1C). These results suggested that the neurogenic potential of mouse NS cells rapidly decreased with differentiation.
In cell culture, there is an inverse relationship between Ngn expression and the propensity of the neural progenitors to undergo differentiation into astrocytes, suggesting that proneural bHLH factors might act to suppress the formation of astrocytes [43]. In agreement with these observations, the glial marker GFAP was only detected at day 3, in association with decreased levels of Ngn1 and concomitant with a reduction in the number of neurons. Importantly, analysis of NeuN protein expression revealed postmitotic neurons after 6 days of differentiation. Finally, analysis by immunocytochemistry using $\beta$-III tubulin and GFAP markers further confirmed the decreased neurogenic potential of mouse NS cells throughout differentiation, and the generation of glial cells after the peak of neuronal production (Figure 1D).

\section{Apoptosis-associate miRNAs are differentially modulated during mouse neural stem cell differentiation}

miRNAs are thought to play a role in cancer pathogenesis. In fact, a specific subset of miRNAs is upregulated in most cancer profiles, and are, therefore, considered to be antiapoptotic miRNAs [44]. The best characterized of that subgroup are miR-21, miR-222, miR-221, miR-1792 cluster, miR-106 and miR-155. In contrast, proapoptotic miRNAs are usually downregulated in cancer, and include miR-15, miR-16, the let-7 family and members of the miR-34 family. Importantly, we have recently shown that apoptosis-associated factors temporally modulate mouse NS cell differentiation [45]. As miRNAs have recently been implicated in neural differentiation [46], we sought to investigate whether apoptosis-specific miRNAs are particularly relevant during mouse NS cell differentiation.

Global miRNA expression profiling studies revealed differential expression patterns of apoptosis-related miRNAs throughout mouse NS cell differentiation (Tables 1 and 2). In general, let-7 family members were upregulated at 3 days, and decreased at 8 days of differentiation. Interestingly, and similar to $\mathrm{miR}-34 \mathrm{a} / \mathrm{b} / \mathrm{c}, \mathrm{miR}-16$ was upregulated at both 3 and 8 days of neural differentiation. In contrast, antiapoptotic miRNAs were in general downregulated at 8 days. Further analysis of the differentially expressed miRNAs involved clustering analysis into different groups, according to variations in the apoptosis-associated miRNAs expression (Additional file 1). Less differentiated cells (1 and 3 days) were grouped separately from those that were more differentiated (8 days). Importantly, similar grouping was not achieved in clustering analysis using all detected miRNAs.

Based on a possible link between miR-16, let-7a and miR-34a with known apoptotic molecules that have already been associated with differentiation, we decided to validate microarray data for the three proapoptotic 
A

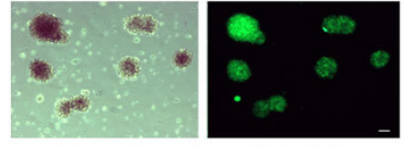

B

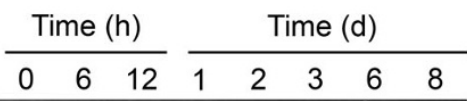

Mash1 $\ldots \ldots-\ldots-137 \mathrm{bp}$

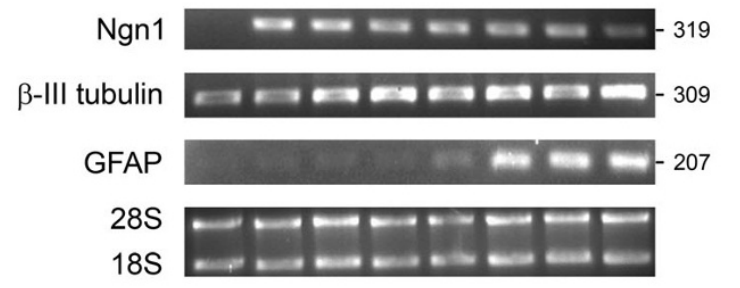

C

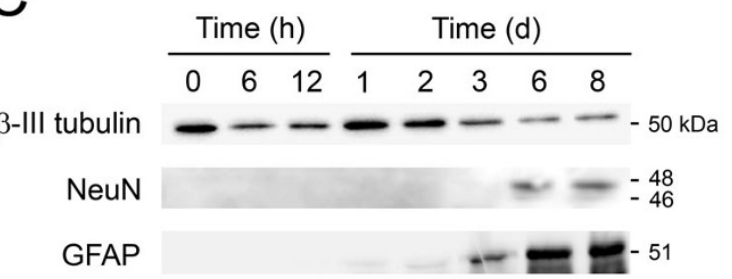

Ponceau S

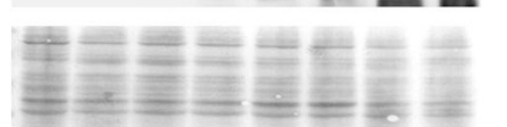

$\mathrm{D}$

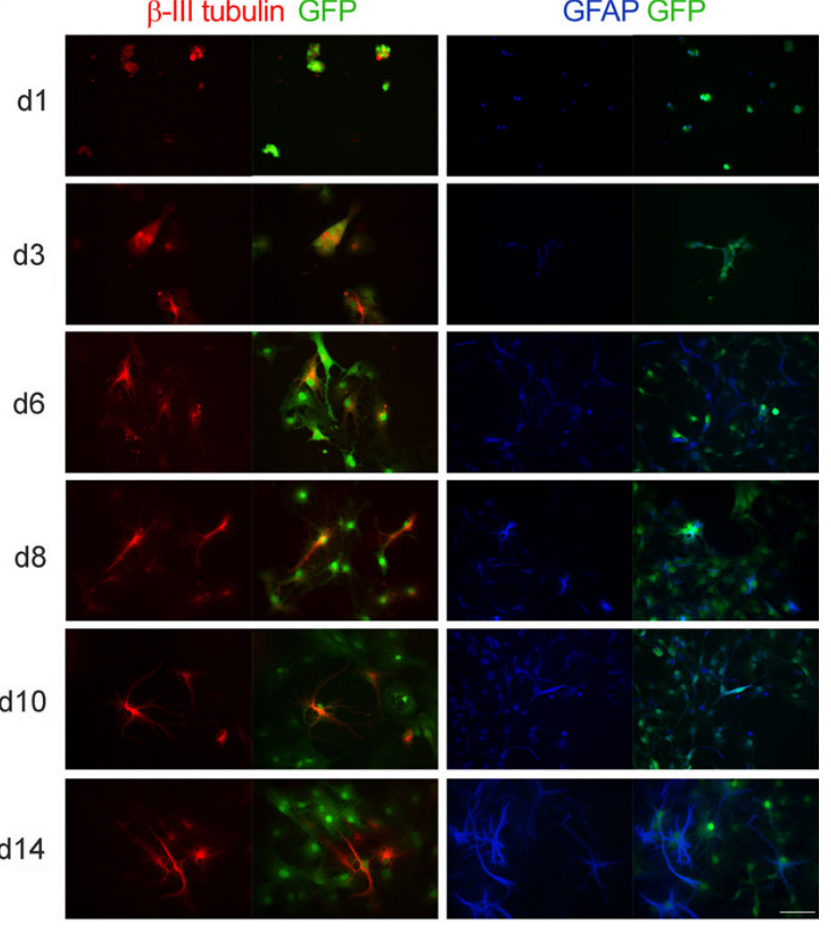

Figure 1 Mouse NS cells have both neurogenic and gliogenic potential in vitro. Mouse NS cells were expanded in the presence of EGF and bFGF, and induced to differentiate as described in Materials and Methods. Cells were harvested for total RNA and protein extraction, or fixed at different time points and processed for immunostaining analysis. Neuronal differentiation was readily detected after incubation in differentiation medium, while glial production was only observed from day 3. A) Mouse NS cells constitutively expressing GFP were grown in suspension as neurospheres that increased in number and size with cell proliferation (phase contrast and GFP fluorescence images). B) Semiquantitative RT-PCR analysis for selected markers of lineage commitment at successive time-points of mouse NS cell differentiation. Neurospheres (undifferentiated NS cells) collected before platting in differentiation medium were considered 0 time differentiation. Data was normalized to 28 S. C) Representative immunoblots showing protein expression of neuronal ( $\beta$-III tubulin and NeuN) and glial (GFAP) markers during mouse NS cell differentiation. Ponceau S was used as loading control. D) Mouse NS cells labeled with anti- $\beta$-III tubulin and anti-GFAP antibodies, to visualize neurons and glial cells, respectively. Representative immunostaining images were from at least 3 independent experiments. Scale bar: 50 mm. Ngn1, neurogenin1; GFAP, glial fibrillary acidic protein; NeuN, neuronal nuclei; h, hours; d, days.

miRNAs throughout mouse NS cell differentiation by quantitative real time-PCR (Figure 2). Antiapoptotic miR-19a and miR-20a, two miR-17-92 cluster members were also investigated. Proapoptotic miRNAs were confirmed to be upregulated during mouse NS cell differentiation. Notably, miR-16 expression levels were significantly increased from 12 hours to 3 days of differentiation, when compared with undifferentiated cells $(p<0.05)$ (Figure 2). Still, its expression levels remained elevated throughout differentiation. Similarly, let-7a was significantly upregulated following induction of differentiation, increasing almost 4- and 3-fold at 6 and 12 hours, respectively $(p<0.05)$. After returning to basal levels at day 2 , let-7a expression was again significantly upregulated at day 3 and 6 , by 2.6- and 3.5-fold, respectively $(p<0.05)$, slightly decreasing at day $8(p<0.01)$. miR-34a, in turn, was modulated primarily beyond the third day of differentiation. After a 3-fold increase at 3 days $(p<0.01)$, miR-34a was further upregulated at day 6 by $\sim 11$-fold $(p<0.001)$, comparing with 

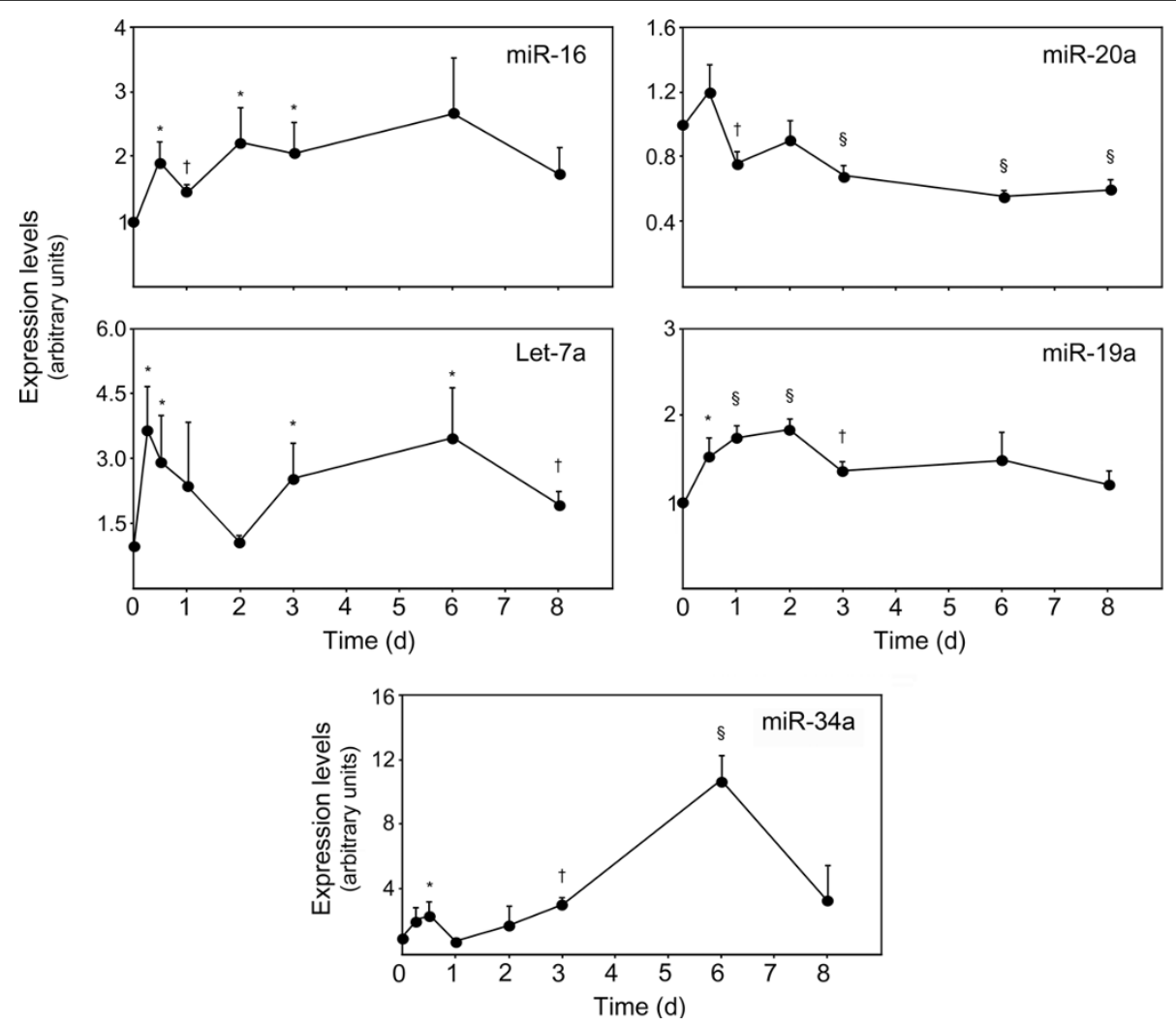

Figure 2 Apoptosis-associated miRNAs are modulated during mouse NS cell differentiation. Expression of specific proapoptotic (miR-16, let-7a and miR-34a) and antiapoptotic miRNAs (miR-20a and miR-19a) were analyzed by quantitative Real Time-PCR from 10 ng of total RNA using specific Taqman primers and GAPDH for normalization. ${ }^{*} p<0.05, t p<0.01$ and $\$ p<0.001$ compared to day 0 (undifferentiated cells). Expression levels were calculated by the $\triangle \triangle C \mathrm{Ct}$ method using undifferentiated cells as calibrator. Data represent mean \pm SEM of four independent experiments.

undifferentiated cells. Similarly to miR-16 and let-7a, a decrease in miR-34a expression occurred from day 6 to day 8 .

The synchronous induction of proapoptotic miRNAs suggested that they may play a role during mouse NS cell differentiation. In contrast, antiapoptotic miR-20a was mainly downregulated throughout neural differentiation. In fact, its expression levels were $\sim 2$-fold downregulated from 6 days and beyond $(p<0.001)$, compared to undifferentiated cells. Curiously, miR-19a expression was mostly increased during the first 3 days of differentiation, gradually decreasing toward control levels. The onset of miR-19a expression correlates with induction of proliferation during the first 3 days of differentiation (data not shown).

Expression of apoptosis-related miRNAs is not associated with increased cell death during mouse NS cell differentiation

To exclude the possibility that expression of proapoptotic miRNAs is associated with increased cell death, we evaluated cellular apoptosis during mouse NS cell differentiation using Hoechst staining, TUNEL assay and cytofluorometric analysis. Undifferentiated cells exhibited major apoptosis-associated alterations, including chromatin condensation and nuclear fragmentation (Figure 3A, Hoechst), DNA fragmentation (Figure 3A, TUNEL), exposure of phosphatidylserine on the outer leaflet of the plasma membrane (detected with annexin V-APC conjugates) (Figure $3 \mathrm{~B}$ and $3 \mathrm{C}$ ), as well as membrane permeabilization, as indicated by the staining with the vital dye PI. Importantly, induction of cell differentiation resulted in minor alterations in nuclear morphology, while DNA fragmentation was slightly detected during the first two days of differentiation. In addition, phosphatidylserine exposure was only slightly increased from day 3 to day 6 , but always less than $6 \%$ during differentiation. Furthermore, no significant loss of cell viability was observed. Taken together, our results indicated that differentiation of mouse NSC was not associated with a significant increase of cell death.

All three proapoptotic miRNAs increased from day 3 to day 6 of differentiation. In addition, a concomitant increase in cell death was also observed. Thus, to 
A
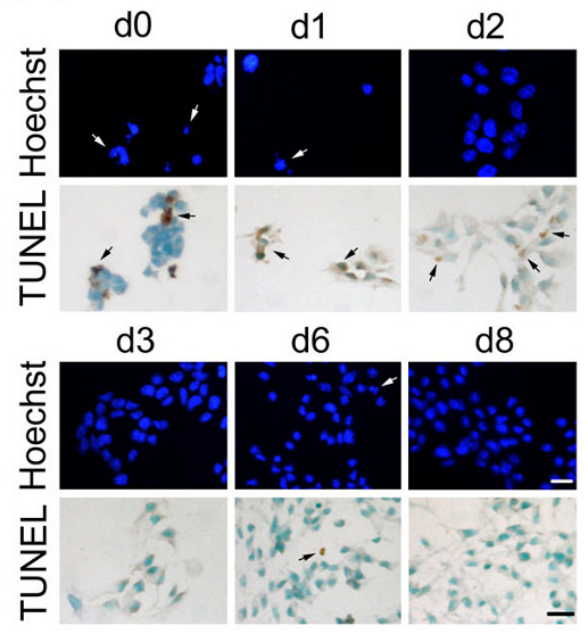

B

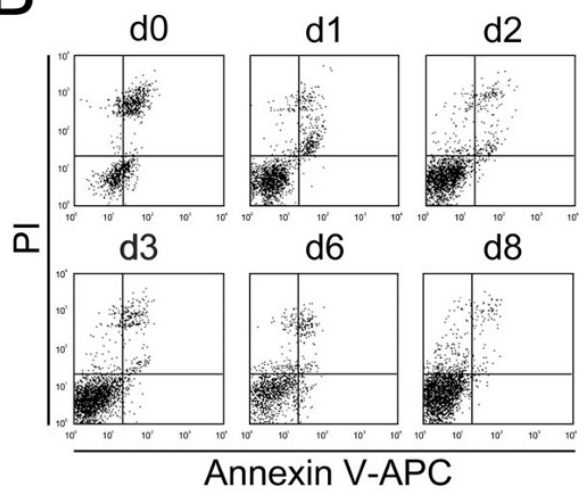

C

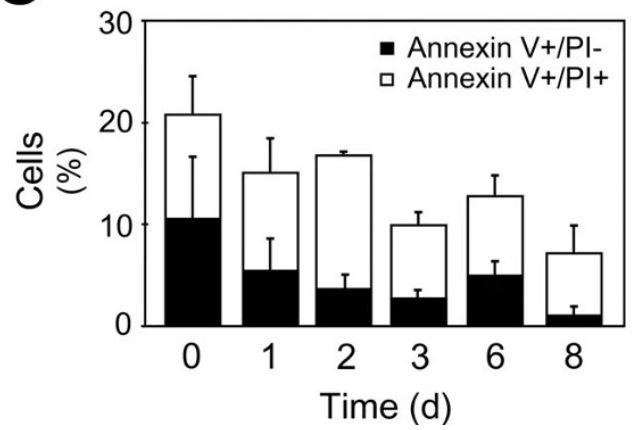

Figure 3 Differentiation of mouse NS cells is not associated with increased cell death. Mouse NS cells at different days of differentiation were fixed and processed for either morphological evaluation of apoptosis or TUNEL assay, or were stained with Annexin-V-APC/PI. A) Evaluation of apoptosis by Hoechst staining and TUNEL assay. Representative images from at least three independent experiments. Arrows indicate apoptotic cells. B) Representative FACS diagrams depicting the percentages of either dying (Annexin+/PI-) or dead (Annexin+/PI+) cells. C) Quantitation of the data depicted in FACS diagrams. Results are mean \pm SEM. This experiment was repeated at least three times, yielding comparable results. Scale bar: $10 \mu \mathrm{m}$. d, days. exclude the role of these specific miRNAs in apoptosis, we inhibited apoptosis at 6 days and reevaluated changes on miRNA expression (Figure 4). Incubation with the antiapoptotic TUDCA for 72 hours, reduced Annexin+/PI- cells from 6.4\% to 5.3\% (Figure 4A and $4 \mathrm{~B})$. In addition, loss of cell viability (Annexin+/PI+ cells) was significantly reduced from $14.2 \%$ to $10.6 \%$ $(p<0.05)$. More importantly, the decrease in cell death after TUDCA treatment did not decrease the expression of proapoptotic miRNAs (Figure 4C). These results strongly suggested that modulation of miR-16, let-7a and miR-34a was most likely due to cell differentiation rather than cell death.

\section{Apoptosis-associated miRNAs are upregulated in different} models of neural differentiation

To further validate the role of the proapoptotic miRNAs, miR-16, let-7a and miR-34a in neural cell differentiation, we investigated whether they were upregulated in other neural differentiation models, including mouse ES cells, PC12 and NT2N cell lines. The generation of neurons from ES cells has reproducibly been characterized in vitro [32,33]. Neural progenitors derived from ES cells organize themselves into rosette-like structures that can subsequently differentiate into neurons, astrocytes and oligodendrocytes. Using the same differentiation protocol, neurogenesis was evidenced by increased Ngn2 and $\beta$-III tubulin mRNA expression levels at 8 days of differentiation (Figure 5A). The neural progenitor marker Nestin was also increased, suggesting a concomitant increase in neural progenitors. In fact, at this stage of differentiation, expression levels of miR-16, let-7a and miR-34a were increased when compared with day 4 (Figure 5B). The inhibition of Notch pathway at 8 days of differentiation by LY411575 treatment resulted in increased neuronal production. In fact, neuronal markers, particularly Ngn2, were increased, and morphological evaluation was consistent with the presence of differentiated cells (Figure 5A and 5C). Notably, LY411575-induced neurogenesis resulted in a significant increased of miR-16 and miR-34a, by 3- and 2-fold (Figure $5 \mathrm{~B})$, respectively $(p<0.05)$, supporting the potential involvement of both miRNAs in neuronal differentiation. Glial differentiation was not detected in the time points analyzed (data not shown).

It has been previously described that differentiation of PC12 cells can be induced by NGF [47]. Cell differentiation increases during the first 7 days of treatment with NGF, as measured by neuronal outgrowth and mRNA levels of specific neurofilaments [48]. Moreover, this correlation decreases with lower NGF concentrations. Our results demonstrated that treatment of PC12 cells with $50 \mathrm{ng} / \mathrm{ml}$ of NGF markedly induced miR-16 expression at 2 and 4 days, compared with NGF-untreated cells 

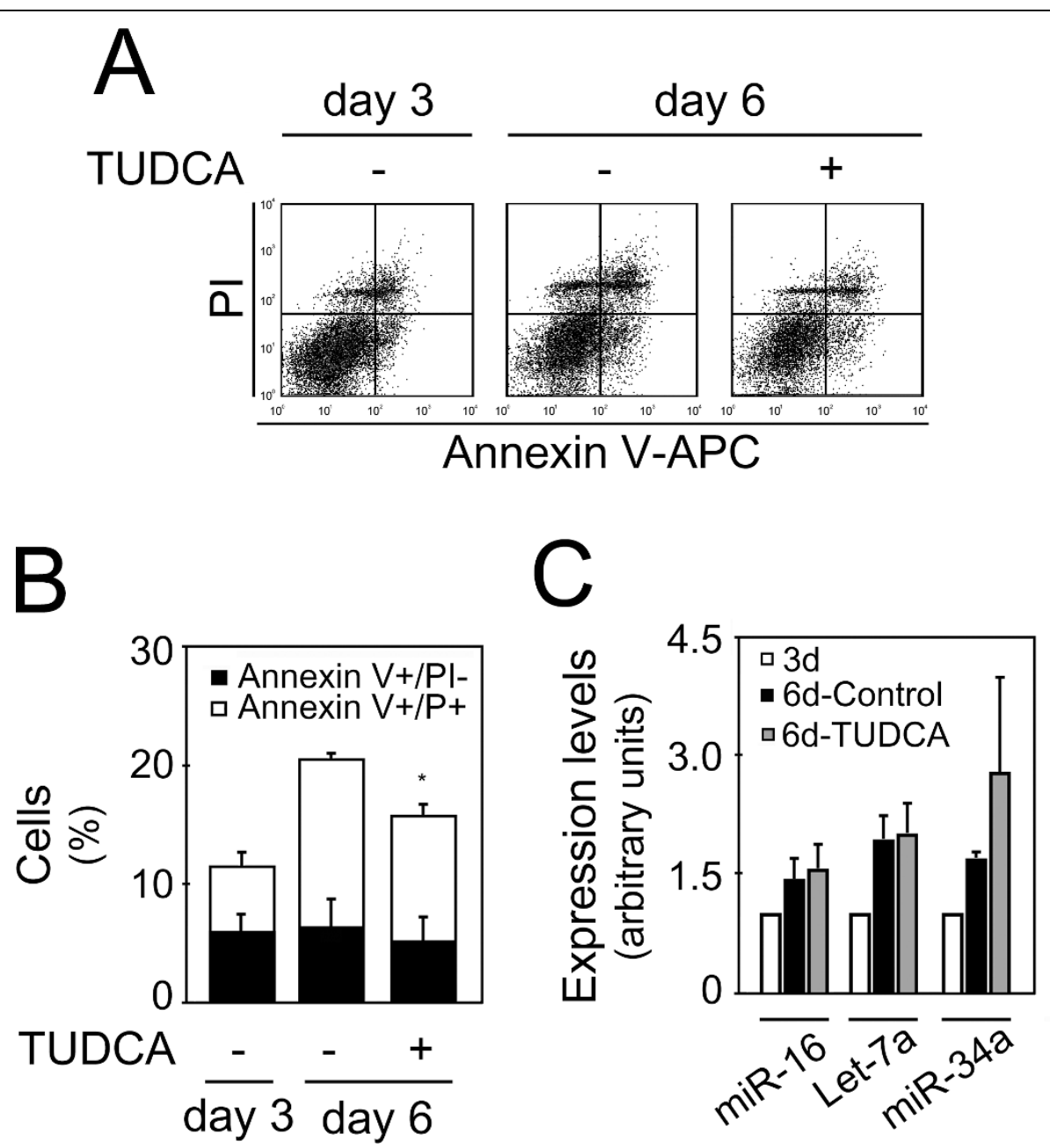

Figure 4 Inhibition of apoptosis by TUDCA was not associated with a decrease in proapoptotic miRNAs expression. Mouse NS cells with 3 days of differentiation were either untreated or treated with $50 \mu \mathrm{M}$ of TUDCA for 72 hours. Collected cells were stained with Annexin-VAPC/PI to evaluate cell death, or processed for total RNA extraction and miRNAs expression evaluation by quantitative Real Time-PCR. A) Representative Annexin V-APC/PI stainings showing decreased cell death after TUDCA incubation. B) Quantitation of either dying (Annexin+/PI-) or dead (Annexin+/PI+) cells depicted in FACS diagrams. Results are mean \pm SEM of triplicates. C) Expression of proapoptotic miRNAs at 3 and 6 days, with or without TUDCA treatment. miR-16, let-7a and miR-34a expression were evaluated from $10 \mathrm{ng}$ of total RNA, using specific primers for each miRNA, and GAPDH for normalization. Expression levels were calculated by the $\triangle \triangle C$ t method using differentiated cells at 3 days as calibrator. Data represent mean \pm SEM of three independent experiments. ${ }^{*} p<0.05$ compared to respective nontreated cells at 6 days.

(Figure 6A). Indeed, miR-16 expression increased by 1.8$(p<0.01)$ and $1.4-$ fold $(p<0.05)$ at 2 and 4 days, respectively. Nevertheless, no difference in miR-16 expression levels was detected at 7 days, under different NGF treatments. Interestingly, 24 hours after treatment with $50 \mathrm{ng} /$ $\mathrm{ml}$ of NGF, let-7a expression was $\sim 5$-fold upregulated in differentiated PC12 cells $(p<0.05)$. Under identical conditions, let-7a expression remained elevated throughout the time course $(p<0.05)$. Notably, miR-34a expression was also gradually upregulated after NGF treatment. Although to a lesser extent, similar results were obtained for all three miRNAs under suboptimal NGF $5 \mathrm{ng} / \mathrm{ml}$ concentrations. None of the selected miRs were modulated in NGF-untreated cells.
Human teratocarcinoma NT2 cells generate postmitotic neurons (NT2N) in response to retinoic acid and mitotic inhibitors [49]. Retinoic acid treatment of NT2 cells induced neuronal differentiation as evidenced by the expression of the neuronal marker NeuroD at 14 and 21 days, as well as increased expression of $\beta$-III tubulin (data not shown). In NT2N, miR-16 expression was increased by 3.6 -fold at day $14(p<0.001)$ and almost 4 -fold at day $21(p<0.05)$ of differentiation (Figure 6B). Similarly, let-7a was highly upregulated, particularly at 21 days of retinoic acid treatment $(p<$ $0.05)$. In contrast, miR-34a was not modulated during cell differentiation. Replated cells showed increased differentiation, as evidenced by the increase in $\beta$-III 

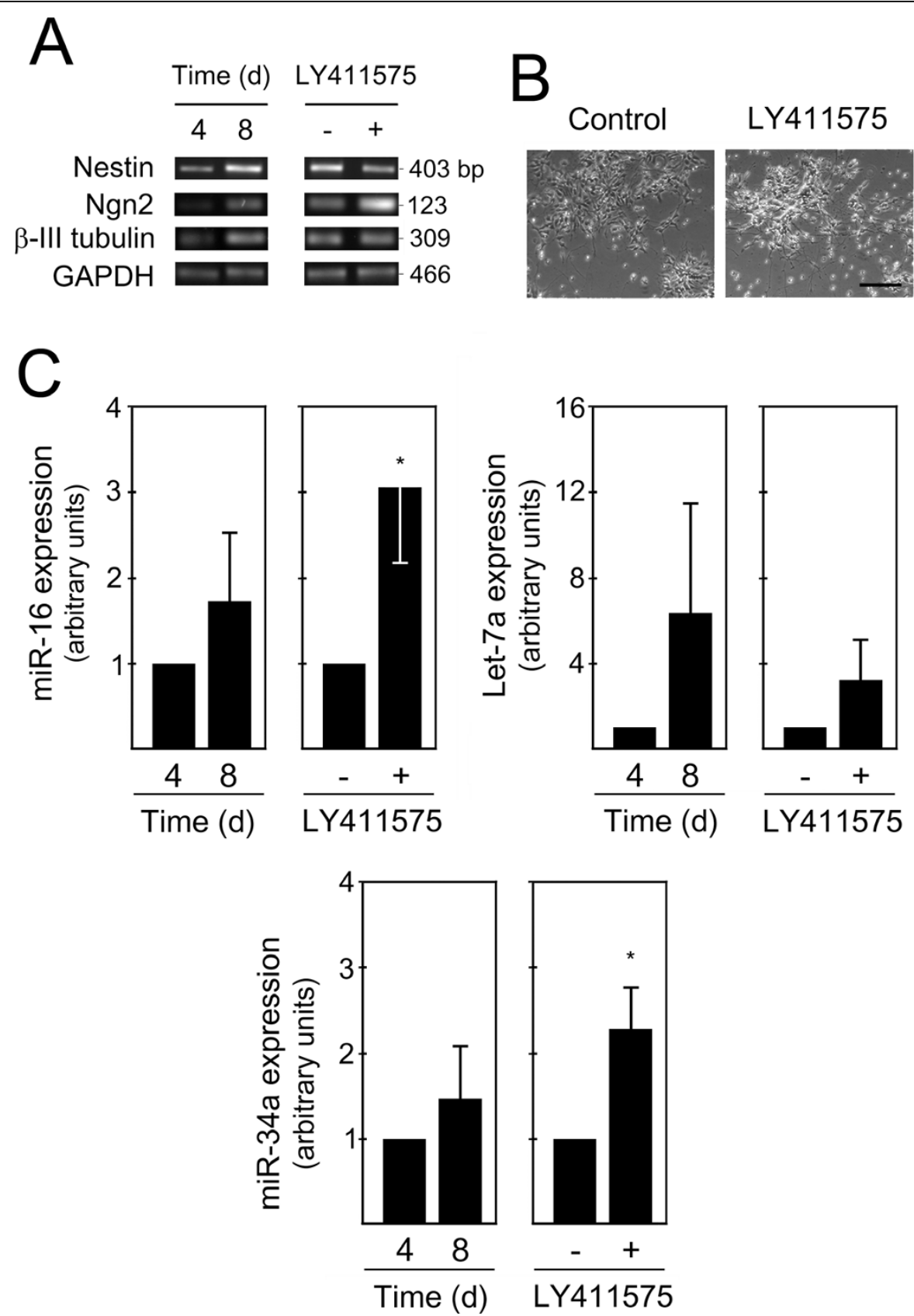

Figure 5 miR-16, let-7a and miR-34a are increased during mouse ES cell differentiation. Mouse ES cells (Sox1-GFP 46C) were differentiated using an adherent monolayer protocol. Cells at 4 and 8 days were collected for total RNA extraction and subsequently processed for evaluation of specific differentiation markers, as well as proapoptotic miRNA expression by quantitative Real Time-PCR. A positive control for neural differentiation was also performed at day 8 by treating cells with either $10 \mathrm{nM}$ LY411575 or 0.01\%DMSO (control) for 12 hours. A) Semiquantitative RT-PCR analysis for selected markers of lineage commitment in day 4 and 8, as well as in LY411575-treated and untreated cells. B) Representative bright-field, phase contrast images showing increased neuronal differentiation after LY411575 incubation compared with control (DMSO-treated) cells. C) Expression of miR-16, Let-7a and miR-34a at 4 and 8 days of ES cell differentiation and in control (DMSO-treated) and LY411575-treated rosette cultures at 8 days. miRNAs expression were evaluated from 10 ng of total RNA, using specific primers for each miRNA, and GAPDH for normalization. Expression levels were calculated by the $\triangle \triangle C \mathrm{Ct}$ method using either differentiated cells at 4 days or LY411575untreated cells as calibrator. Data represent mean \pm SEM of three independent experiments. ${ }^{*} p<0.05$ compared to respective nontreated cells. Scale bar: $50 \mu \mathrm{m}$. d, days. 


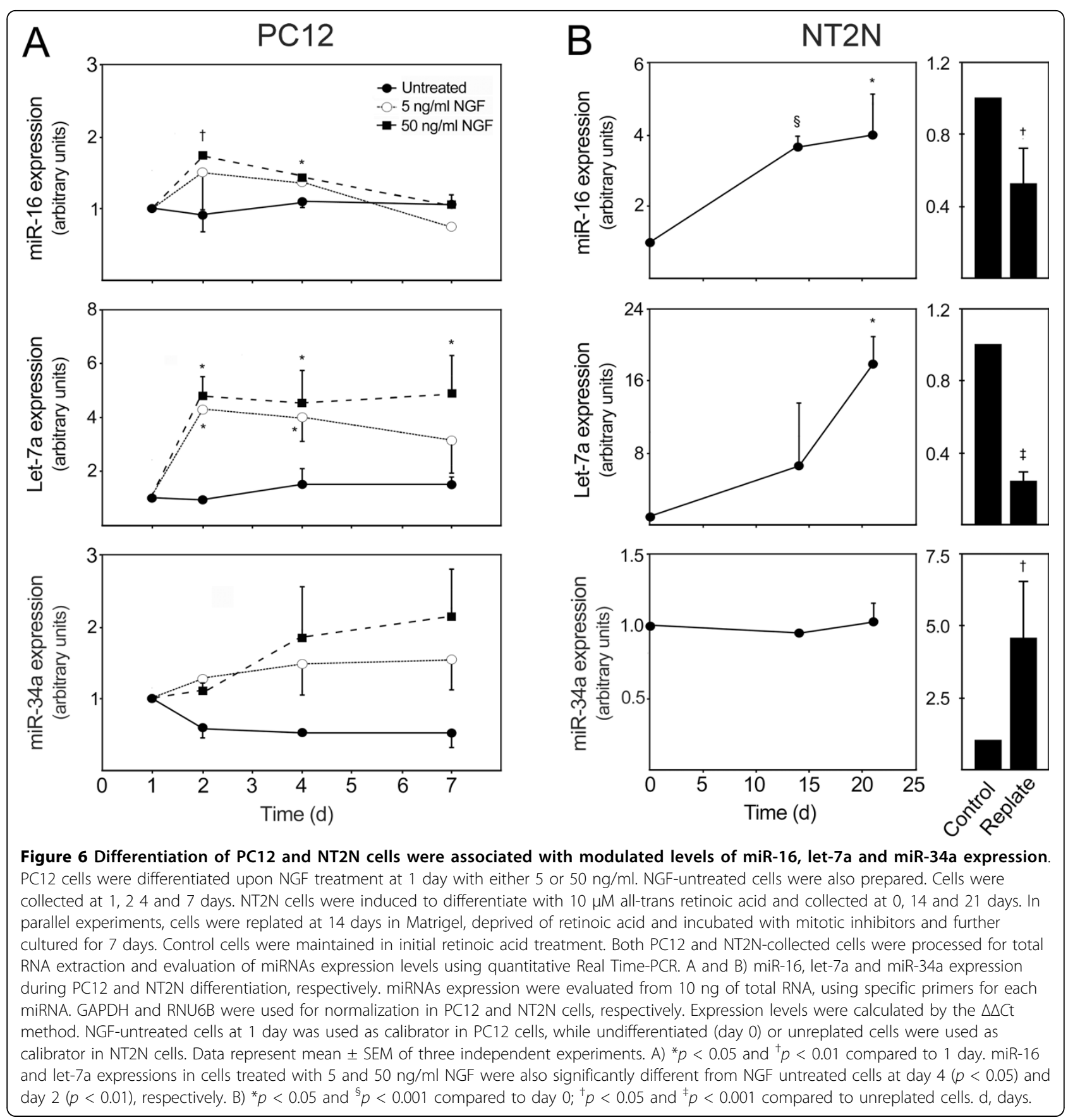

tubulin-positive cells and detection of NeuN-positive cells (data not shown). Surprisingly, increased differentiation after replating was associated with a significant decrease in both miR-16 and let-7a expression by $\sim 2$ $(p<0.05)$ and 5-fold $(p<0.001)$, while miR-34a increased by 4.5 -fold $(p<0.05)$, compared with nonreplated cells.

miR-34a was the most significantly upregulated miRNA during mouse NS cell differentiation $(\sim 11$-fold between days 3 and $6 ; p<0.001)$ compared to other apoptosis-associated miRNAs. Because miR-34a upregulation coincides with the onset of postmitotic neurons, we investigated the effect of miR-34a upregulation in this population by evaluating NeuN expression. We used flow cytometry to determine the proportion of the postmitotic neuronal population (Additional file 2). The proportion of NeuN-positive cells was significantly increased when compared to cells transfected with unrelated RNA duplexes (Figure 7A). In fact, NeuN-positive cells increased from 29.7 to $38.9 \% 24 \mathrm{~h}$ after 


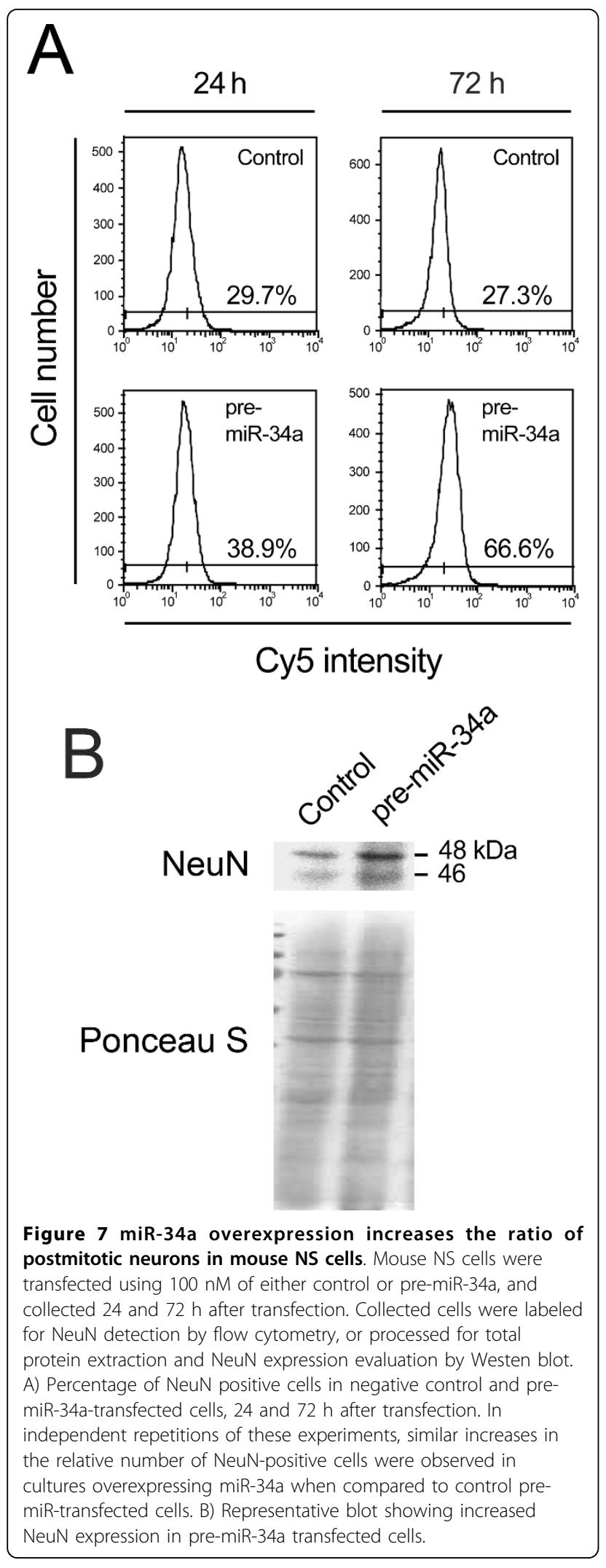

transfection. This increase was further enhanced from 27.3 to $66.6 \%$ at $72 \mathrm{~h}$ post-transfection. In addition, these results were confirmed by Western blot analysis (Figure 7B). No changes were detected in the proportion of astrocytes in the pre-miR-34a transfected cells (data not shown). These results indicated that miR-34a contributes to neuronal differentiation in mouse NS cells.

\section{Discussion}

Differentiation of NS and ES cells in vitro has attracted wide interest as an experimental system for investigating specific molecular pathways of cell development. Here, we have demonstrated neuronal and glial conversion of mouse NS cells. In this model, the neuronal population is formed mainly during the first 2 days, as indicated by the upregulation of $\beta$-III tubulin. Nevertheless, commitment to mature neurons was confirmed by the expression of NeuN at 6 days, which indicates the presence of immature postmitotic neurons. Astrocytic population peaked at 6 days, and this was maintained throughout differentiation.

Functional studies of apoptosis-associated miRNAs have focused intensely on cancer research. However, our results demonstrate that specific miRNAs regulating pro-and antiapoptotic genes may also participate in differentiation processes. The involvement of miR-16 in cell differentiation has not been previously reported. Indeed, miR-16 expression was markedly increased throughout mouse, rat and human neural differentiation. Nevertheless, the onset of miR-16 expression during mouse NS cell differentiation was not associated with the appearance of any specific cell type. miR-16 was shown to be implicated in cell cycle regulation, as well as apoptosis induction by targeting Bcl-2 [25-28]. Apoptosis is not markedly regulated during mouse NS cell differentiation, and Bcl-2 expression is increased (data not shown). Therefore, a possible role for miR-16 in the context of differentiation may be associated with cell cycle control in downregulating the proliferation potential of differentiating cells. During differentiation of neural precursors, a tightly coordinated regulation of cell cycle exit is crucial for the generation of appropriate number of neurons and proper wiring of neuronal circuits [50]. Nevertheless, here-to-fore unrecognized miR-16 targets may exert distinct, yet crucial functions during cell differentiation.

The let-7 family consists of eleven very closely related genes [51]. They are highly conserved in animals from worms to humans, and their expression increases after differentiation and maturation of tissues [52]. In addition to regulating apoptosis by targeting caspase-3 [10], it was also demonstrated that let-7 family members 
regulate RAS and HMGA2 oncogene through the 3'UTR [53-55]. In the present study, let-7a expression was shown to be cyclic during mouse NS cells differentiation, and corresponded to the onset of neurogenesis and gliogenesis. This suggests that let-7a expression is associated with a general mechanism of differentiation rather than differentiation of specific cell types. Our results are supported by the previous report showing that let-7a is a critical regulator of neuronal differentiation $[12,13]$. In fact, increased let-7a expression during ES cells, PC12 and NT2N differentiation also underscores the important role of let-7a during general differentiation. Additional studies are warranted to evaluate the mechanism(s) by which let-7a regulates cell differentiation. Importantly, although highly modulated during cell differentiation, both let-7a and miR-16 were significantly expressed in neurospheres (data not shown). Therefore, it is possible that additional mechanisms exist to antagonize let-7a and miR-16 expression during NS cell differentiation.

A specific role for miR-34a during neuronal differentiation has not been reported. Interestingly, herein we showed a significant upregulation of miR-34a during mouse NS cell differentiation, and this paralleled the appearance of postmitotic neurons. In addition, in vitro transient overexpression of miR-34a increased the proportion of NeuN-positive cells. Given that miR-34a has been shown to regulate genes involved in cell cycle arrest, it is possible that miR-34a upregulation is related to cell cycle exit and the subsequent appearance of immature postmitotic neurons. In fact, miR-34a upregulation in ES cells after LY treatment, as well as in NT2N cells after incubation with the mitosis inhibitor, supports this hypothesis. In addition, it has been previously shown that miR-34a can suppress cell-cycle genes and induce neural phenotype in neuroblastoma tumors [56]. Importantly, it has been previously reported that miR34a overexpression had no effect on cell cycle arrest and survival/apoptosis of astrocytes [57,58]. However, additional studies are required to confirm the influence of miR-34a in neurogenesis and evaluate whether it mediates p53 effects on cell differentiation. In fact, several potential miR-34a targets might be involved in the transition towards postmitotic neurons. It was previously demonstrated that miR-34a targets Sirt1 and is regulated by $\mathrm{p} 53$, which in turn, is activated by Sirt1 suppression [59]. In addition, miR-34a may also regulate the differentiation process by influencing Notch signaling pathway $[57,60]$. In contrast to let-7a and miR-16, miR-34a was barely detected in undifferentiated cells, supporting its specific involvement in cell differentiation.

miR-19a and miR-20a are members of the miR-17-92 cluster [61], which consists of seven mature miRNAs, previously linked to tumorigenesis. Recently, additional functions have been assigned to this cluster, particularly to miR-20a and miR-19a. Specifically, miR-20a was shown to control monocyte differentiation [62]. In fact, transfection of hematopoietic progenitors with miR-20a increased the proliferation of monocytes and blocked differentiation, whereas inhibition of miR-20a caused a decrease in proliferation and more rapid differentiation and maturation. Our results, showing that miR-20a decreases during mouse NS cell differentiation, are in agreement with this previous report.

Only limited information is available regarding the physiological role of miR-19a. It has been demonstrated that it acts as a positive regulator of antiapoptotic Stat3/ IL-6 receptor signaling by directly suppressing SOCS-1, thereby facilitating malignant growth of multiple myeloma [63]. Further, miR-19 appears to affect the level of proapoptotic protein Bim, thereby preventing apoptosis and promoting cell survival. The possible role of miR19a on cell survival, may explain why this miRNA was upregulated at early stages after the induction of mouse NS cell differentiation. However, additional studies are required to determine the specific role of both miR-20a and miR-19a during cell differentiation, and also evaluate if their expression is restricted to a specific cell type.

\section{Conclusions}

In conclusion, our results demonstrate that apoptosisassociated miRNAs are differentially expressed during neural differentiation, in the absence of cell death, and identify miR-16, let-7a and miR-34a as important players.

\section{Additional material}

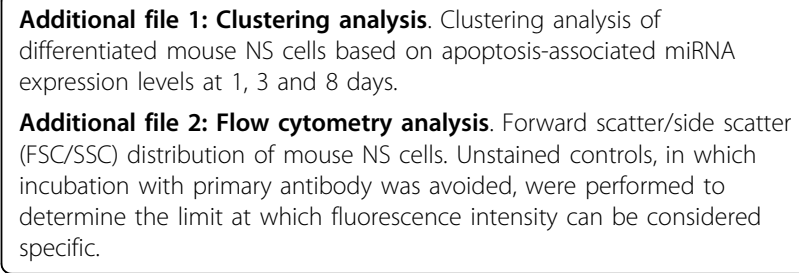

\section{Abbreviations}

NS cells: neural stem cells; ES cells: embryonic stem cells; GFP: green fluorescent protein; miR or miRNA: microRNA.

\section{Acknowledgements}

We would like to acknowledge Yan Zeng (University of Minnesota Medical School, Minneapolis, Minnesota, USA) for miRNA expression profiling, and Rui Castro (iMed.UL, Lisbon, Portugal) for microarray data analysis. The authors thank Ricardo Viana and Inês Milagre (iMed.UL, Lisbon, Portugal) for providing PC12 and NT2N cell cultures, and Domingos Henrique (IMM, Lisbon, Portugal) for ES cell lines. This work was supported by grant PTDC/ BIA-BCM/67922/2006 from Fundação para a Ciência e a Tecnologia (FCT), Lisbon, Portugal. MM Aranha and DM Santos are recipients of PhD 
fellowships from FCT, Portugal (SFRH/BD/28429/2006 and SFRH/BD/42008/ 2007, respectively).

\section{Author details}

'Research Institute for Medicines and Pharmaceutical Sciences, Faculty of Pharmacy, University of Lisbon, Lisbon 1649-003, Portugal. "Department of Neurosurgery, University of Minnesota Medical School, Minneapolis, MN 55455, USA. ${ }^{3}$ Stem Cell Institute, University of Minnesota Medical School, Minneapolis, MN 55455, USA. ${ }^{4}$ Department of Medicine, University of Minnesota Medical School, Minneapolis, MN 55455, USA. ${ }^{5}$ Department of Genetics, Cell Biology, and Development, University of Minnesota Medical School, Minneapolis, MN 55455, USA.

\section{Authors' contributions}

MMA carried out mouse NS cell culture studies, RNA isolation, and real time PCR assays and drafted the manuscript. DMS performed mouse ES cell cultures, respective characterization, and RNA isolation. JMX was involved in mouse NS cell characterization. SS and CMPR were involved in experimental design and interpretation of the data. WCL, CJS, SS and CMPR contributed to the manuscript. All authors read and approved the final manuscript.

Received: 3 June 2010 Accepted: 24 September 2010

Published: 24 September 2010

\section{References}

1. Doetsch F: The glial identity of neural stem cells. Nature Neuroscience 2003, 6:1127-1134.

2. Temple S: Stem cell plasticity-building the brain of our dreams. Nature Reviews 2001, 2:513-520.

3. Maimets T, Neganova I, Armstrong L, Lako M: Activation of $\mathrm{p} 53$ by nutlin leads to rapid differentiation of human embryonic stem cells. Oncogene 2008, 27:5277-5287.

4. Porrello A, Cerone MA, Coen S, Gurtner A, Fontemaggi G, Cimino L, Piaggio $G$, Sacchi A, Soddu S: $p 53$ regulates myogenesis by triggering the differentiation activity of pRb. Journal of Cell Biology 2000, 151:1295-1304.

5. Fernando $P$, Brunette $S$, Megeney LA: Neural stem cell differentiation is dependent upon endogenous caspase 3 activity. FASEB Journal 2005, 19:1671-1673.

6. Zhang $K Z$, Westberg $J A$, Holtta $E$, Andersson $L C$ : BCL2 regulates neural differentiation. Proceedings of the National Academy of Sciences of the United States of America 1996, 93:4504-4508.

7. Ambros V: The functions of animal microRNAs. Nature 2004, 431:350-355.

8. Bartel DP: MicroRNAs: genomics, biogenesis, mechanism, and function. Cell 2004, 116:281-297.

9. Du T, Zamore PD: microPrimer: the biogenesis and function of microRNA. Development 2005, 132:4645-4652.

10. Tsang WP, Kwok TT: Let-7a microRNA suppresses therapeutics-induced cancer cell death by targeting caspase-3. Apoptosis 2008, 13:1215-1222.

11. Reinhart BJ, Slack FJ, Basson M, Pasquinelli AE, Bettinger JC, Rougvie AE, Horvitz HR, Ruvkun G: The 21-nucleotide let-7 RNA regulates developmental timing in Caenorhabditis elegans. Nature 2000, 403:901-906

12. Liu SP, Fu RH, Yu HH, Li KW, Tsai CH, Shyu WC, Lin SZ: MicroRNAs regulation modulated self-renewal and lineage differentiation of stem cells. Cell Transplantation 2009, 18:1039-1045.

13. Sempere LF, Freemantle S, Pitha-Rowe I, Moss E, Dmitrovsky E, Ambros V: Expression profiling of mammalian microRNAs uncovers a subset of brain-expressed microRNAs with possible roles in murine and human neuronal differentiation. Genome Biology 2004, 5:R13.

14. Bommer GT, Gerin I, Feng Y, Kaczorowski AJ, Kuick R, Love RE, Zhai $Y$, Giordano TJ, Qin ZS, Moore BB, et al: p53-mediated activation of miRNA34 candidate tumor-suppressor genes. Current Biology 2007, 17:1298-1307.

15. Chang TC, Wentzel EA, Kent OA, Ramachandran K, Mullendore M, Lee KH, Feldmann G, Yamakuchi M, Ferlito M, Lowenstein CJ, et al: Transactivation of miR-34a by p53 broadly influences gene expression and promotes apoptosis. Molecular Cell 2007, 26:745-752.

16. Corney DC, Flesken-Nikitin A, Godwin AK, Wang W, Nikitin AY: MicroRNA$34 \mathrm{~b}$ and MicroRNA-34c are targets of $\mathrm{p} 53$ and cooperate in control of cell proliferation and adhesion-independent growth. Cancer Research 2007, 67:8433-8438.
17. He L, He X, Lim LP, de Stanchina E, Xuan Z, Liang Y, Xue W, Zender L, Magnus J, Ridzon D, et al: A microRNA component of the p53 tumour suppressor network. Nature 2007, 447:1130-1134.

18. Raver-Shapira N, Marciano E, Meiri E, Spector Y, Rosenfeld N, Moskovits N, Bentwich Z, Oren M: Transcriptional activation of miR-34a contributes to p53-mediated apoptosis. Molecular Cell 2007, 26:731-743.

19. Tarasov V, Jung P, Verdoodt B, Lodygin D, Epanchintsev A, Menssen A Meister $\mathrm{G}$, Hermeking H: Differential regulation of microRNAs by $\mathrm{p} 53$ revealed by massively parallel sequencing: miR-34a is a $p 53$ target that induces apoptosis and G1-arrest. Cell Cycle 2007, 6:1586-1593.

20. Sun F, Fu H, Liu Q, Tie Y, Zhu J, Xing R, Sun Z, Zheng X: Downregulation of CCND1 and CDK6 by miR-34a induces cell cycle arrest. FEBS Letters 2008, 582:1564-1568

21. Welch C, Chen Y, Stallings RL: MicroRNA-34a functions as a potential tumor suppressor by inducing apoptosis in neuroblastoma cells. Oncogene 2007, 26:5017-5022.

22. Navarro F, Gutman D, Meire E, Caceres M, Rigoutsos I, Bentwich Z, Lieberman J: miR-34a contributes to megakaryocytic differentiation of K562 cells independently of p53. Blood 2009, 114:2181-2192.

23. Hashimi ST, Fulcher JA, Chang MH, Gov L, Wang S, Lee B: MicroRNA profiling identifies miR-34a and miR-21 and their target genes JAG1 and WNT1 in the coordinate regulation of dendritic cell differentiation. Blood 2009, 114:404-414.

24. Tarantino C, Paolella G, Cozzuto L, Minopoli G, Pastore L, Parisi S, Russo T: miRNA 34a, 100, and 137 modulate differentiation of mouse embryonic stem cells. FABEB Journal 2010.

25. Cimmino A, Calin GA, Fabbri M, lorio MV, Ferracin M, Shimizu M, Wojcik SE, Aqeilan Rl, Zupo S, Dono M, et al: miR-15 and miR-16 induce apoptosis by targeting BCL2. Proceedings of the National Academy of Sciences of the United States of America 2005, 102:13944-13949.

26. Linsley PS, Schelter J, Burchard J, Kibukawa M, Martin MM, Bartz SR, Johnson JM, Cummins JM, Raymond CK, Dai H, et al: Transcripts targeted by the microRNA-16 family cooperatively regulate cell cycle progression. Molecular and Cellular Biology 2007, 27:2240-2252.

27. Liu Q, Fu H, Sun F, Zhang H, Tie Y, Zhu J, Xing R, Sun Z, Zheng X: miR-16 family induces cell cycle arrest by regulating multiple cell cycle genes. Nucleic Acids Research 2008, 36:5391-5404.

28. Chen RW, Bemis LT, Amato CM, Myint H, Tran H, Birks DK, Eckhardt SG, Robinson WA: Truncation in CCND1 mRNA alters miR-16-1 regulation in mantle cell lymphoma. Blood 2008, 112:822-829.

29. Reynolds BA, Weiss S: Generation of neurons and astrocytes from isolated cells of the adult mammalian central nervous system. Science 1992, 255:1707-1710

30. Reynolds BA, Weiss S: Clonal and population analyses demonstrate that an EGF-responsive mammalian embryonic CNS precursor is a stem cell. Developmental Biology 1996, 175:1-13.

31. Rietze R, Reynolds B: Neural stem cell isolation and characterization Method in Enzymology 2006, 419:3-23.

32. Ying QL, Stavridis M, Griffiths D, Li M, Smith A: Conversion of embryonic stem cells into neuroectodermal precursors in adherent monoculture. Nature Biotechnology 2003, 21:183-186.

33. Abranches E, Silva M, Pradier L, Schulz H, Hummel O, Henrique D, Bekman E: Neural differentiation of embryonic stem cells in vitro: a road map to neurogenesis in the embryo. PloS One 2009, 4:e6286.

34. Cheung WM, Fu WY, Hui WS, Ip NY: Production of human CNS neurons from embryonal carcinoma cells using a cell aggregation method. BioTechniques 1999, 26:946-948, 950-942, 954.

35. Megiorni F, Mora B, Indovina P, Mazzilli MC: Expression of neuronal markers during NTera2/cloneD1 differentiation by cell aggregation method. Neuroscience Letters 2005, 373:105-109.

36. Kalscheuer $S$, Zhang X, Zeng $Y$, Upadhyaya P: Differential expression of microRNAs in early-stage neoplastic transformation in the lungs of F344 rats chronically treated with the tobacco carcinogen 4(methylnitrosamino)-1-(3-pyridyl)-1-butanone. Carcinogenesis 2008, 29:2394-2399.

37. Thomson JM, Parker J, Perou CM, Hammond SM: A custom microarray platform for analysis of microRNA gene expression. Nature Methods 2004, 1:47-53.

38. Romero-Calvo I, Ocon B, Martinez-Moya P, Suarez MD, Zarzuelo A, MartinezAugustin O, de Medina FS: Reversible Ponceau staining as a loading 
control alternative to actin in Western blots. Analytical Biochemistry 401:318-320.

39. Schutte B, Nuydens R, Geerts H, Ramaekers F: Annexin V binding assay as a tool to measure apoptosis in differentiated neuronal cells. Journal of Neuroscience Methods 1998, 86:63-69.

40. Alvarez-Buylla A, Garcia-Verdugo JM: Neurogenesis in adult subventricular zone. Journal Neuroscience 2002, 22:629-634.

41. Tropepe V, Sibilia M, Ciruna BG, Rossant J, Wagner EF, van der Kooy D: Distinct neural stem cells proliferate in response to EGF and FGF in the developing mouse telencephalon. Developmental Biology 1999, 208:166-188.

42. Qian X, Shen Q, Goderie SK, He W, Capela A, Davis AA, Temple S: Timing of CNS cell generation: a programmed sequence of neuron and glial cell production from isolated murine cortical stem cells. Neuron 2000, 28:69-80.

43. Sun $Y$, Nadal-Vicens M, Misono S, Lin MZ, Zubiaga A, Hua X, Fan G, Greenberg ME: Neurogenin promotes neurogenesis and inhibits glial differentiation by independent mechanisms. Cell 2001, 104:365-376.

44. Garofalo M, Condorelli GL, Croce CM, Condorelli G: MicroRNAs as regulators of death receptors signaling. Cell Death and Differentiation 17:200-208.

45. Aranha MM, Sola S, Low WC, Steer CJ, Rodrigues CM: Caspases and p53 modulate $\mathrm{FOXO} 3 \mathrm{~A} / \mathrm{ld} 1$ signaling during mouse neural stem cell differentiation. Journal of Cellular Biochemistry 2009, 107:748-758.

46. Li X, Jin P: Roles of small regulatory RNAs in determining neuronal identity. Nature Reviews 11:329-338.

47. Greene $L A$, Tischler AS: Establishment of a noradrenergic clonal line of rat adrenal pheochromocytoma cells which respond to nerve growth factor. Proceedings of the National Academy of Sciences of the United States of America 1976, 73:2424-2428.

48. Schimmelpfeng J, Weibezahn KF, Dertinger H: Quantification of NGFdependent neuronal differentiation of PC-12 cells by means of neurofilament-L mRNA expression and neuronal outgrowth. Journal of Neuroscience Methods 2004, 139:299-306.

49. Hara K, Yasuhara T, Maki M, Matsukawa N, Masuda T, Yu SJ, Ali M, Yu G, Xu L, Kim SU, et al: Neural progenitor NT2N cell lines from teratocarcinoma for transplantation therapy in stroke. Progress in Neurobiology 2008, 85:318-334.

50. Politis PK, Thomaidou D, Matsas R: Coordination of cell cycle exit and differentiation of neuronal progenitors. Cell Cycle 2008, 7:691-697.

51. Pasquinelli AE, Reinhart BJ, Slack F, Martindale MQ, Kuroda Ml, Maller B, Hayward DC, Ball EE, Degnan B, Muller P, et al: Conservation of the sequence and temporal expression of let-7 heterochronic regulatory RNA. Nature 2000, 408:86-89.

52. Lee YS, Kim HK, Chung S, Kim KS, Dutta A: Depletion of human micro-RNA miR-125b reveals that it is critical for the proliferation of differentiated cells but not for the down-regulation of putative targets during differentiation. Journal of Biological Chemistry 2005, 280:16635-16641.

53. Akao $Y$, Nakagawa $Y$, Naoe T: let-7 microRNA functions as a potential growth suppressor in human colon cancer cells. Biological \& Pharmaceutical Bulletin 2006, 29:903-906.

54. Johnson SM, Grosshans H, Shingara J, Byrom M, Jarvis R, Cheng A, Labourier E, Reinert KL, Brown D, Slack FJ: RAS is regulated by the let-7 microRNA family. Cell 2005, 120:635-647.

55. Lee YS, Dutta A: The tumor suppressor microRNA let-7 represses the HMGA2 oncogene. Genes \& Development 2007, 21:1025-1030.

56. Wei JS, Song YK, Durinck S, Chen QR, Cheuk AT, Tsang P, Zhang Q, Thiele CJ, Slack A, Shohet J, et al: The MYCN oncogene is a direct target of miR-34a. Oncogene 2008, 27:5204-5213.

57. Guessous F, Zhang Y, Kofman A, Catania A, Li Y, Schiff D, Purow B, Abounader R: microRNA-34a is tumor suppressive in brain tumors and glioma stem cells. Cell Cycle 2010.

58. Li Y, Guessous F, Zhang Y, Dipierro C, Kefas B, Johnson E, Marcinkiewicz L, Jiang J, Yang Y, Schmittgen TD, et al: MicroRNA-34a inhibits glioblastoma growth by targeting multiple oncogenes. Cancer Research 2009 69:7569-7576

59. Yamakuchi M, Ferlito M, Lowenstein CJ: miR-34a repression of SIRT1 regulates apoptosis. Proceedings of the National Academy of Sciences of the United States of America 2008, 105:13421-13426.

60. Hermeking $\mathrm{H}$ : The miR-34 family in cancer and apoptosis. Cell Death and Differentiation 17:193-199.
61. Bonauer A, Dimmeler S: The microRNA-17-92 cluster: still a miRacle? Cell Cycle 2009, 8:3866-3873.

62. Fontana L, Pelosi E, Greco P, Racanicchi S, Testa U, Liuzzi F, Croce CM, Brunetti E, Grignani F, Peschle C: MicroRNAs 17-5p-20a-106a control monocytopoiesis through AML1 targeting and M-CSF receptor upregulation. Nature Cell Biology 2007, 9:775-787.

63. Pichiorri F, Suh SS, Ladetto M, Kuehl M, Palumbo T, Drandi D, Taccioli C, Zanesi $\mathrm{N}$, Alder $\mathrm{H}$, Hagan JP, et al: MicroRNAs regulate critical genes associated with multiple myeloma pathogenesis. Proceedings of the National Academy of Sciences of the United States of America 2008, 105:12885-12890.

doi:10.1186/1471-2164-11-514

Cite this article as: Aranha et al:: Apoptosis-associated microRNAs are modulated in mouse, rat and human neural differentiation. BMC

Genomics 2010 11:514.

\section{Submit your next manuscript to BioMed Central and take full advantage of:}

- Convenient online submission

- Thorough peer review

- No space constraints or color figure charges

- Immediate publication on acceptance

- Inclusion in PubMed, CAS, Scopus and Google Scholar

- Research which is freely available for redistribution 